Original Article

\title{
PROTECTIVE ROLE OF DAIDZEIN AGAINST CYCLOPHOSPHAMIDE INDUCED NEPHROTOXICITY IN EXPERIMENTAL RATS
}

\author{
SANJIV KARALE ${ }^{* 1}$, JAGADISH V. KAMATH ${ }^{2}$ \\ ${ }^{1}$ Research Scholar, PRIST University, Thanjavur, Tamilnadu, 2Pharmacology Department, Shree Devi College of Pharmacy, Mangalore, \\ Karnataka \\ Email: sanjiv.karale@gmail.com
}

Received: 16 Mar 2017 Revised and Accepted: 20 Apr 2017

\begin{abstract}
Objective: To evaluate the protective effect of daidzein on cyclophosphamide (CPA) induced nephrotoxicity in experimental rats.

Methods: The Wistar rats of either sex were randomly divided into five equal groups: Group I (normal saline $1 \mathrm{ml} \mathrm{p.} \mathrm{o.),} \mathrm{Group} \mathrm{II} \mathrm{(CPA} 150 \mathrm{mg} / \mathrm{mg}$ i. p), Group III (Daidzein $20 \mathrm{mg} / \mathrm{kg} \mathrm{p.} \mathrm{o.+CPA} 150 \mathrm{mg} / \mathrm{kg}$, i. p.), Group IV (Daidzein $40 \mathrm{mg} / \mathrm{kg} \mathrm{p.} \mathrm{o.+CPA} 150 \mathrm{mg} / \mathrm{kg}$, i. p.) and Group V (Daidzein 40 $\mathrm{mg} / \mathrm{kg} \mathrm{p.} \mathrm{o.,} \mathrm{alone).} \mathrm{Rats} \mathrm{of} \mathrm{all} \mathrm{groups} \mathrm{except} \mathrm{Group} \mathrm{I} \mathrm{and} \mathrm{Group} \mathrm{V} \mathrm{treated} \mathrm{with} \mathrm{CPA} \mathrm{in} \mathrm{a} \mathrm{dosage} \mathrm{of} 150 \mathrm{mg} / \mathrm{kg}$ i. p in the last five days of treatment. Blood samples were collected on $11^{\text {th }}$ day from each rat and subjected for the evaluation of serum markers such as Serum creatinin, serum urea and serum uric acid. Kidney of each rat was excised and subjected for antioxidant parameters evaluation such as malonyl dialdehyde (MDA), glutathione (GSH), superoxide dismutase (SOD), catalase and histopathological study.
\end{abstract}

Results: Daidzein explored a significant $(\mathrm{P}<0.001)$ role in $\mathrm{CPA}$-induced nephrotoxicity by suppressing serum creatinine, serum urea and serum uric acid. Daidzein also demonstrated significant $(\mathrm{P}<0.001)$ protection against $\mathrm{CPA}$-induced nephrotoxicity by decreasing $\mathrm{MDA}$ level and by elevating the GSH, SOD, catalase at different doses.

Conclusions: The obtained results of present study revealed that daidzein attenuates the CPA-induced nephrotoxicity by antioxidant defence action in rats.

Keywords: Daidzein, Cyclophosphamide, Serum creatinin, Glutathione, Nephrotoxicity

(C) 2017 The Authors. Published by Innovare Academic Sciences Pvt Ltd. This is an open access article under the CC BY license (http://creativecommons.org/licenses/by/4.0/) DOI: http://dx.doi.org/10.22159/ijpps.2017v9i6.18516

\section{INTRODUCTION}

The renal system is the major target area for numerous toxic xenobiotics which comprises of environmental chemicals, metals and anticancer agents, antibiotics and other drugs [1]. Chemotherapy is the multimodal approach in the oncological therapy which involves more complex regimens and thereby tends highly susceptible towards toxic effects [2]. Commonly anticancer drugs act by interfering with the growth of tumour cells. Further, their toxic effects are not restricted to cancer cells but also extend to normal cells leads to different types of disease conditions [3].

Cyclophosphamide (CPA) is a broad-spectrum potent anticancer drug. CPA is effective against lymphoma, leukemia, breast, lung, prostate, myeloma and ovarian cancers and non-malignant disorders like rheumatoid arthritis and vasculitis [1, 3]. The usage of CPA is severely limited because of its widespread physiological adverse effects such as hepatic injury, nephrotoxicity, cardiotoxicity, myelosuppression, immunotoxicity, urotoxicity, lung injury, mutagenicity, teratogenicity and other side effects like nausea, vomiting and alopecia [4]. It has been already proved that elevation of reactive oxygen species (ROS) by CPA in renal tissues play a pivot role in the pathogenesis of CPA-induced nephrotoxicity [1].

Flavonoids are the polyphenolic, dietary molecules and rich antioxidants usually found in fruits, flowers and vegetables. These are considered potent chemo preventive molecules because of their hydrogen donating and metal chelating capacities. Recent studies demonstrated that anticancer drugs in combination with detoxifying agents, flavonoids such as morin, rutin, hespiridin, genistein etc, and protective agents reduces the toxicities induced by cancer chemotherapy $[4,5]$.

Daidzein is a phytoestrogen most commonly found in red clover (Trifolium pratense), alfalfa (Medicago sativa), soya (soybeans and soya foods) and some legumes (Leguminosae). Daidzein is a polyphenolic flavonoid belongs to isoflavone group; a pivot circulating iso-flavone in people receiving more soy diet. It has already evidenced its beneficial effects against the cancers of breast, ovary, chest, large intestine and prostate gland. It also possesses estrogenic, anti-inflammatory, cardioprotection, hypoglycaemic, neuroprotective and free radical scavenging actions. And also it plays a vital role in the prevention of osteoporosis and menopausal symptoms. Moreover, in our previous studies daidzein explored its protection against hemotoxicity and hepatotoxicity induced by anticancer agent cisplatin by antioxidant action [6-9].

The current study was aimed to evaluate the possible protective action of daidzein against CPA-induced nephrotoxicity in experimental rats.

\section{MATERIALS AND METHODS}

\section{Animals}

Healthy adult wistar rats of either sex weighing 170-220g were chosen for the study and were procured from animal house of Shree Devi College of pharmacy, Mangalore. They were acclimatized to laboratory conditions of ambient temperature $\left(25 \pm 2{ }^{\circ} \mathrm{C}\right), 30-70 \%$ humidity and $12 \mathrm{hr}$ light-dark cycles. The rats were categorised into experimental and control groups and housed in sanitized polypropylene cages containing sterile paddy husk as bedding. They had free accessed to standard pellets as basal diet and water ad libitum. The experimental protocol was approved by Institutional Animal Ethical Committee, Shree Devi College of pharmacy (SDCP/IAEC-04/2014-15), Mangalore, Karnataka, as per the guidance of committee for the purpose of control and supervision of experiments in animals (CPCSEA), Government of India.

\section{Chemicals}

Cyclophosphamide was procured from Sigma Aldrich, Bangalore and other chemicals used were of analytical grade and obtained from standard companies. Biochemical kits for the evaluation of serum markers (serum creatinin, urea and uric acid) were procured from Robonik India, Pvt Ltd, Mumbai. 


\section{Experimental design}

The present research study was designed for $11 \mathrm{~d}$. Daidzein was isolated from soybeans by solvents (chloroform and ethyl acetate) using soxhlet apparatus and identified by high-performance liquid chromatography (HPLC) method [10]. The experimental rats were categorised into five groups of 6 animals in each after one-week acclimatization.

Group 1(Normal): rats were received with normal saline $1 \mathrm{ml}$, p. o. for 10 days.

Group 2 (Cyclophosphamide): rats were received CPA (150 $\mathrm{mg} / \mathrm{kg}$, i. p) in last five days, after successive administration of distilled water ( $1 \mathrm{ml}$, orally).

Group 3 (CPA+Daidzein $20 \mathrm{mg} / \mathbf{k g}$ ): rats were received with daidzein $40 \mathrm{mg} / \mathrm{kg}$, p. o for 10 days and received CPA $(150 \mathrm{mg} / \mathrm{kg}$, i. p) in last five days.

Group 4 (CPA+Daidzein $40 \mathrm{mg} / \mathrm{kg}$ ): rats were received with daidzein $40 \mathrm{mg} / \mathrm{kg}$, p. o for 10 days and received CPA $(150 \mathrm{mg} / \mathrm{kg}$, i. p) in last five days.

Group 5 (Daidzein $40 \mathrm{mg} / \mathrm{kg}$ alone): rats were received with daidzein $40 \mathrm{mg} / \mathrm{kg}$, p. o for $10 \mathrm{~d}$.

After the completion of $10 \mathrm{~d}$ treatment with test drugs, on $11^{\text {th }}$ day the animals of all groups were sacrificed by ether inhalation. Blood was collected from each rat by intracardiac puncture, heparinised and centrifuged at $3000 \mathrm{rpm}$ for $15 \mathrm{~min}$. The serum (supernatant) was collected and used for the estimation of serum biomarkers. Kidney of each rat was isolated, separated from their surrounding connective tissue, washed and cleaned with normal saline solution. Later renal tissues were blotted using filter paper to remove traces of blood, weighed and rinsed in ice-cold saline. Half portion of each kidney was homogenized for endogenous antioxidants analysis and the other half portion was processed for histological study [1].

\section{Estimation of serum biomarkers and endogenous antioxidants}

\section{Assessment of serum biomarkers}

The level serum marker such as creatinine, urea and uric acid in heparinised serum samples were determined by using commercial kits (Robonik) by using semi auto analyser (Robonik).

\section{Estimation of oxidative stress markers}

Half portion of the kidney of each rat was homogenized in ice-cold $10 \%$ trichloroacetic acid phosphate buffer and saline $(0.05 \mathrm{M}$, $\mathrm{pH7.4)}$. The renal homogenates were centrifuged for $15000 \mathrm{rpm}$ for $15 \mathrm{~min}$. The obtained supernatants were used for estimations of GSH, MDA, SOD and catalase by colorimetric method. The GSH level of renal tissue was determined according to Ellmanns method [11].
The concentration of lipid peroxides was analyzed by estimating MDA using the Ohkawa et al. procedure [12]. Catalase enzyme activity was measured by Aebi method [13]. And SOD activity in renal tissues was assessed based by the method described by Kakkar et al. [14].

\section{Histopathological study}

Specimens of renal tissues of each group were fixed in $10 \%$ buffered formalin and processed with paraffin wax. For histopathological feature examination, $5 \mu \mathrm{m}$ sections were stained with hematoxylin and eosin for the examination using light microscope [15].

\section{Statistical analysis}

The data obtained by the various parameters was statistically evaluated by one-way analysis of variance (ANOVA) followed by Tukey-Kramer multiple comparison tests. The mean values \pm SEM were calculated for each parameter [16].

\section{RESULTS}

\section{Estimation of serum biomarkers}

A significant $(\mathrm{P}<0.001)$ protection was explored on serum markers in daidzein pre-treated animals against CPA-induced disruption on renal system and results data was shown in table 1 . A significant $(\mathrm{P}<0.001)$ rise in serum creatinine, urea and uric acid content was exhibited in CPA alone treated group compared to the normal group. The pre-treatment with daidzein at both doses $(20 \mathrm{mg} / \mathrm{kg}$ and 40 $\mathrm{mg} / \mathrm{kg})$ groups showed a significant $(\mathrm{P}<0.001)$ depletion in the level creatinine, urea and uric acid compared to CPA alone treated groups. And there was no significant change in between of normal group and daidzein alone treated group in serum marker level.

\section{Assessment of endogenous antioxidants}

The pre-treatment with daidzein revealed significant $(\mathrm{P}<0.001)$ beneficial role on endogenous antioxidants against CPA-induced nephrotoxicity and results were mentioned in table 2 . A significant $(\mathrm{P}<0.001)$ decline in GSH was observed in CPA alone treated groups compared to normal groups. The pre-treated with daidzein animals exhibit a significant $(\mathrm{P}<0.001)$ elevation in GSH compared to CPA alone treated groups. In CPA alone treated groups a significant $(\mathrm{P}<0.001)$ increase in MDA content was observed compared to the normal group. In Daidzein pre-treated groups significant $(\mathrm{P}<0.001)$ decrease in lipid peroxidaion was observed compared to CPA alone treated group.

There was significant $(\mathrm{P}<0.001)$ fall in SOD and catalase was found in $\mathrm{CPA}$ alone treated animals compared to normal rats. The pre-treated with daidzein groups were explored significant $(\mathrm{P}<0.001)$ rise in SOD and catalase compared to CPA alone treated animals. And there was no significant difference in the values of all endogenous antioxidants in between normal group and daidzein alone treated animals.

Table 1: Effect of daidzein on serum markers in CPA induced nephrotoxicity

\begin{tabular}{llllll}
\hline Treatment & Normal & Cyclophosphamide & Daidzein20/mg/kg+CPA & Daidzein40 mg/kg+CPA & Daidzein (40 mg/kg) alone \\
\hline Serum Creatinine & $0.97 \pm 0.08$ & $4.21 \pm 0.11^{\# \# \#}$ & $2.73 \pm 0.10^{* * * \# \# \#}$ & $1.18 \pm 0.06^{* * *}$ & $0.91 \pm 0.07^{* * *}$ \\
Serum Urea & $38.2 \pm 0.43$ & $72.25 \pm 0.26^{\# \# \#}$ & $48.75 \pm 0.31^{* * * \# \# \#}$ & $40.77 \pm 0.28^{* * \# \# \# \#}$ & $38.57 \pm 0.38^{* * * *}$ \\
Uric acid & $2.5 \pm 0.10$ & $6.83 \pm 0.13^{\# \# \#}$ & $4.45 \pm 0.12^{* * * \# \# \#}$ & $2.97 \pm 0.08^{* * * \#}$ & $2.58 \pm 0.07^{* * * *}$ \\
\hline
\end{tabular}

$\mathrm{n}=6$, Values were expressed in mean \pm SEM, one way ANOVA followed by Tukey-Kramer multiple comparison test.*** $<0.001$ when compared to Cyclophosphamide group and $\# \mathrm{P}<0.05$, \#\#\#P<0.001 compared to the normal group.

Table 2: Effect of daidzein on endogenous antioxidants in CPA induced nephrotoxicity

\begin{tabular}{|c|c|c|c|c|c|}
\hline Treatment & Normal & Cyclophosphamide & Daidzein20/mg/kg+CPA & $\begin{array}{l}\text { Daidzein40 } \\
\text { mg/kg+CPA }\end{array}$ & $\begin{array}{l}\text { Daidzein }(40 \mathrm{mg} / \mathrm{kg}) \\
\text { alone }\end{array}$ \\
\hline GSH (ๆM/mg wet gland) & $17.95 \pm 0.21$ & $8.86 \pm 0.13^{\# \# \#}$ & $12.98 \pm 0.10^{* * * \# \# \#}$ & $16.85 \pm 0.20^{* * * \# \# \#}$ & $17.96 \pm 0.14^{* * *}$ \\
\hline MDA ( $\eta \mathrm{M} / \mathrm{mg}$ wet gland) & $6.98 \pm 0.12$ & $16.51 \pm 0.20^{\# \# \# \#}$ & $11.15 \pm 0.10^{* * * \# \# \#}$ & $7.31 \pm 0.11^{* * *}$ & $6.95 \pm 0.12^{* * *}$ \\
\hline SOD (U/mg wet gland) & $96.18 \pm 0.54$ & $49.4 \pm 0.58^{\# \# \#}$ & $73.08 \pm 0.83^{* * * \# \# \#}$ & $91.11 \pm 0.42^{* * * \# \# \#}$ & $96.05 \pm 0.66^{* * *}$ \\
\hline $\begin{array}{l}\text { CATALASE (U/mg wet } \\
\text { gland) }\end{array}$ & $22.9 \pm 0.12$ & $12.01 \pm 0.22^{\# \# \#}$ & 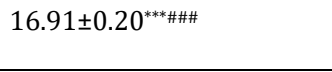 & $21.28 \pm 0.23^{* * * \# \#}$ & $22.81 \pm 0.16^{* * *}$ \\
\hline
\end{tabular}

$\mathrm{n}=6$, Values were expressed in mean \pm SEM, one way ANOVA followed by Tukey-Kramer multiple comparison test.**** $<<0.001$ when compared to

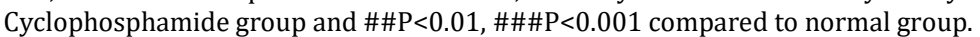




\section{Histopathological study}

The histopathological changes observed in the current study were displayed in fig. 1. The normal architecture of renal cortex with Bowman's capsule was observed in the normal group. In CPA alone treated group revealed inflammatory infiltration, intertubular haemorrhage, a decrease in the size bowman capsule and congestion of renal blood capillaries. The groups pre-treated with daidzein showed a considerable decrease in inflammation, no haemorrhage and no changes with glomerular cortex and bowman capsule appearance. The modulation in renal histopathology with the treatment of daidzein alone remained almost unchanged or same appearance compared to the normal group.

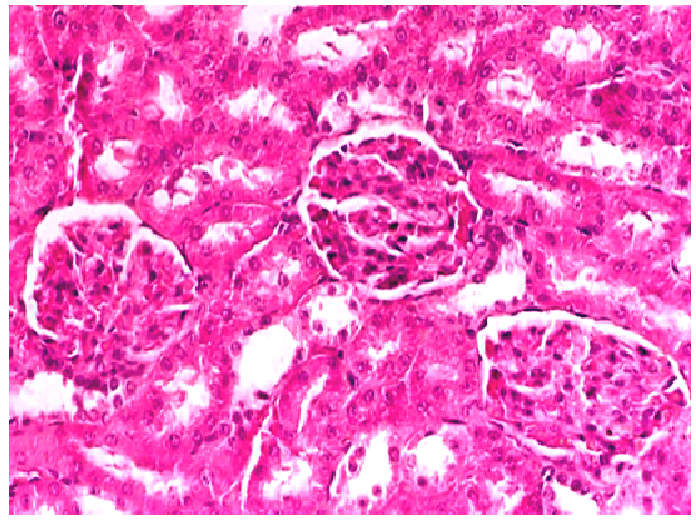

1(a) Normal (normal appearance of renal cortex and tubules, no fatty degeneration and no necrosis)

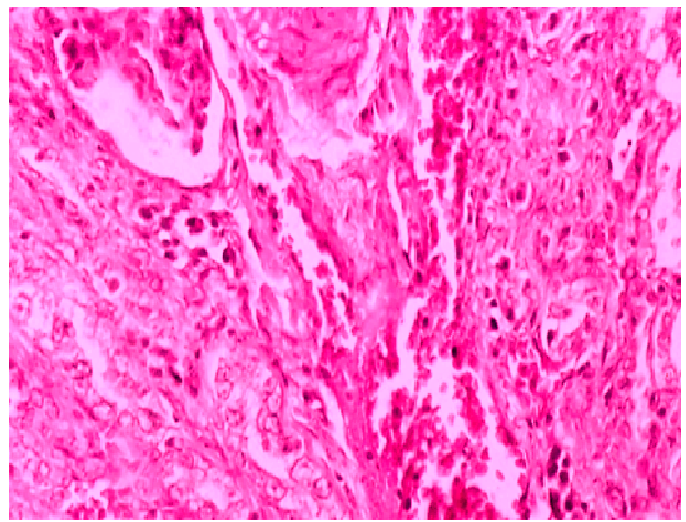

1(b) Cyclophosphamide (CPA)-Alone (disruption renal cortex, congestion of blood vessels, inflammatory infiltration, fatty degeneration)

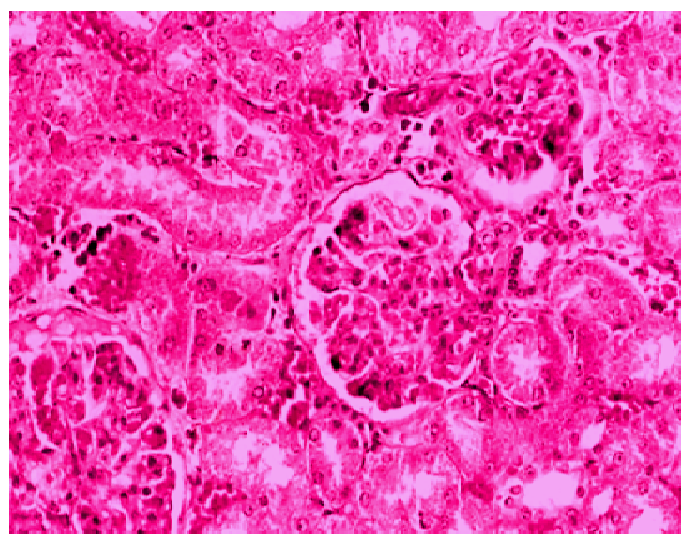

1(c) CPA+Daidzein $20 \mathrm{mg} / \mathrm{kg}$ (mild inflammation, slight fatty degeneration, less vacuolations in cytoplasm)

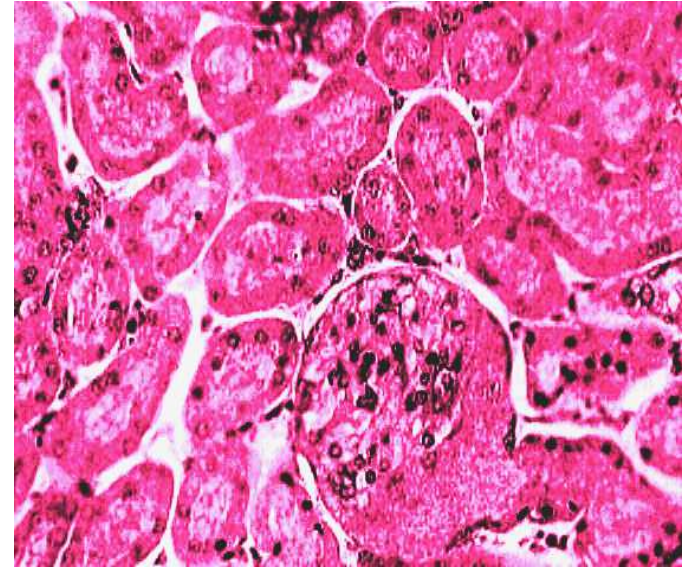

1(d) CPA+Daidzein $40 \mathrm{mg} / \mathrm{kg}$ (cytoplasm well maintained, no inflammation, improved morphology of renal cortex)

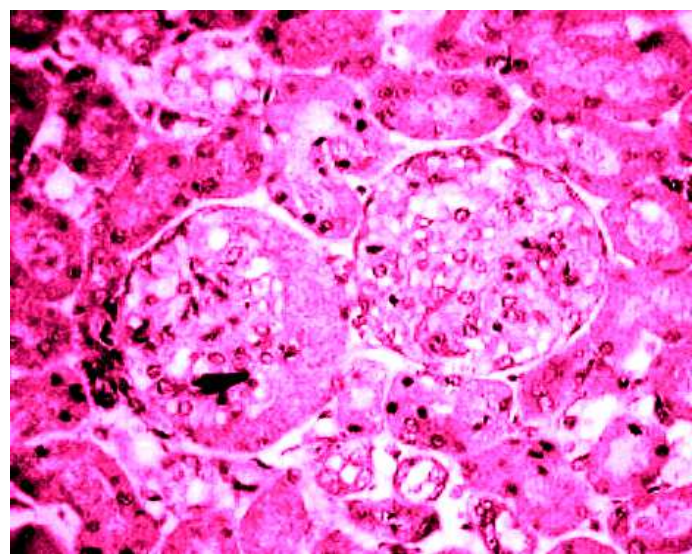

1(e) Daidzein $40 \mathrm{mg} / \mathrm{kg}$-Alone (Normal architecture of cortex and tubules as similar as normal group)

Fig. 1: Histological architecture of renal tissues in different experimental groups ( $\mathrm{H}$ and $\mathrm{E}, \mathrm{X400}$ ). $\mathrm{H}$ and $\mathrm{E}=\mathrm{Hematoxylin}$ and Eosin

\section{DISCUSSION}

The present study has demonstrated the nephron-protective effect of daidzein flavonoid on CPA-induced nephrotoxicity in wistar rats.

Anticancer drugs cause nephrotoxicity at different levels and their deleterious effects ranges from a significant rise in creatinine to kidney failure. Nephrotoxicity is one of the major morbid undesired conditions develops during CPA treatment. It was already documented that CPA administration induces oxidative stress injury leads damage to intercellular organs, lipid peroxidation, the decline in protein synthesis and mitochondrial damage. Severe adverse effects in renal tissues on CPA therapy are mainly because of its toxic metabolites that is phosphoramide and acrolein [17-18].

Nowadays, worldwide increase in evidence of renal injuries and other adverse effects during cancer chemotherapy, it is utmost important to find out complementary antioxidant molecule has the capacity to prevent the renal injuries and other toxicities. In recent studies, flavonoids gained a pivot importance in ameliorating the toxicities produced by CPA and other antineoplastic agents [4, 19]. Daidzein is an isoflavonoid, showed its efficacy in heart disorders, inflammation, atheroscleorosis, osteoporosis, free radical scavenging, diabetes, as antiestrogenic and cancers like breast, lung and prostate cancers $[8,20]$.

In our current study, a significant rise creatinin, urea and uric acid were obsereved in the CPA-treated group. Serum urea and creatinin 
are the major indicators or markers of nephrotoxicity and hepatorenal syndrome. Serum creatinin is the endogenous substance of muscle metabolism and excreted unchanged by the kidney. The elevation in creatinin level in the blood may be due to the abnormality of glomerular filtration process in the kidney $[1,17]$. Urea is the waste substance generated during protein metabolism of proteins by Urea cycle by the liver. The deficiency glomerular filtration rate and a decrease in blood volume leads to increase in urea level in serum [17]. Uric acid is by-product generated during purine biotransformation by the enzyme urate oxidase (uridase). The increase in uric acid level might be due to kidney urate elimination and inefficiency of glomerular filtration in nephrons. Further, it may leads to hyperuricemia due to more tubular reabsorption, mediated by urate exchanger and voltage sensitive urate channel in proximal tubules [1]. The pre-treatment with daidzein successfully ameliorated the elevated levels of creatinin, urea and uric acid induced by CPA.

Oxidative stress injury and generation of reactive oxygen species (ROS) were implicated in the pathogenesis of CPA and other cytotoxic drugs induced nephrotoxicity. Cellular damage occurs due to disruption of dynamic equilibrium between pro-oxidant and free radicals scavenge by antioxidants [21]. In present study, CPA administration leads significant rise in MDA and decline in GSH level. Increase in lipid peroxidation after CPA administration may be due to the influence of activated neutrophiles, macrophages during inflammation or oxidative deterioration of polyunsaturated fatty acids. GSH is considered as the major antioxidant against ROS and vital constituent of detoxification pathways. The depletion in GSH content in renal tissues after CPA therapy is due to the toxic metabolite acrolein. Acrolein binds GSH in the plasma membrane and disrupts antioxidant defense system and elevates the ROS and leads to the necrosis of the tubular cells of kidney $[1,4,17]$. The pre-treatment of daidzein successfully prevent the increased LPO and GSH content induced by CPA. In the current work, a significant decline in SOD and catalase level was observed after CPA administration. SOD and catalase are the vital antioxidant enzymes which converts oxygen molecules into non-toxic products. Increase in LPO and ROS leads to decrease in SOD level. Elevation in the level $\mathrm{H}_{2} \mathrm{O}_{2}$ is due to the inhibition of catalase action. The depletion of catalase in turn also prevents the SOD action. The decline in these antioxidant enzymes is mainly due to more ROS and lipid peroxidation [22]. The pretreatment with daidzein significantly increases the level SOD and catalase after CPA treatment.

The findings of serum markers and antioxidant parameters were correlated with histopathological examination. The CPA therapy exhibit decrease in the size of Bowman's capsule, inflammatory infiltration, congestion and dilatation of blood vessels and atrophy of glomerular apparatus. The pre-treatment with daidzein successfully augmented the toxic effects induced by CPA renal system by exploring beneficial effects such as inhibition of atrophy, no change in the size of Bowman's capsule, slight inflammation and no congestion of blood capillaries.

The pre-treatment with daidzein virtually augmented majority of the deleterious effects produced by CPA. The nephroprotective role of daidzein was evidenced by improvement in the structural architecture of renal profiles, suppression of oxidative stress. Moreover, recent studies of daidzein demonstrated its potential effects in hepatic injury caused by D-galactose-amine and cisplatin by its free radical scavenging action $[9,23]$.

Thus, oral administration of daidzein revealed significant potential effects against deleterious changes in serum markers, antioxidants and histopathology brought by CPA by its inhibitory action on ROS and oxidative stress.

\section{CONCLUSION}

The current study demonstrates that daidzein had positive antioxidant effect against CPA-induced nephrotoxicity, as it alleviates the modifications in serum biomarkers such as creatinine, urea and uric acid as well as oxidative stress markers in renal tissues such as MDA, GSH, SOD and catalase. In future, daidzein may be preferred in combination with anticancer drugs for the treatment of the patients suffering from cancer.

\section{ACKNOWLEDGEMENT}

The authors are thankful to Management of Shree Devi college of pharmacy, Mangalore, India, for their constant encouragement and support and providing all the necessary facilities to carry out of this study.

\section{CONFLICT OF INTERESTS}

Declared none

\section{REFERENCES}

1. Ahmed IA, Sohair RF, Fathi MA, Sara ME. Renoprotective effect of Mangifera indica polysaccharides and silymarin against cyclophosphamide toxicity in rats. J Basic Appl Zool 2015;72:154-62.

2. Deepti C, Harmeet SR, Vibha S, Ritu M. Chemotherapy-induced adverse drug reactions in oncology patients: a prospective observational survey. Indian J Med Paediatr Oncol 2016;37:42-6.

3. Mbong AM, Djiokeng PG, Ntentie FR, Dimodi H, Ngondi JL, Oben EJ. Protective effect of hydroethanolic extracts of Solanum scabrum and Cola verticillata against cyclophosphamide induced toxicity in female rats. J Food Res 2014;3:18-30.

4. Haque R, Hafeez B, Parvez S, Pandey S, Sayeed I, Ali M, et al. Aqueous extract of walnut (Juglans regia L.) protects mice against cyclophosphamide-induced biochemical toxicity. Human Exp Toxicol 2003;22:473-80.

5. Hany AO, Wafaa RM, Hany HA, El-Shaimaa AA. Tangeretin alleviates cisplatin-induced acute hepatic injury in rats: targeting MAPKs and apoptosis. J Pone 2016;1-18. https://doi.org/10.1371/journal.pone.0151649

6. Adem BA. Neuroprotective effects of daidzein on focal cerebral ischemia injury in rats. Neural Regen Res 2015;10:146-52.

7. Yan-Bin Y, Ai-Ling C, Wei L, Shu-Yu Z, Juan L, Jian-Hua G, et al. Daidzein and genistein fail to improve glycemic control and insulin sensitivity in Chinese women with impaired glucose regulation: a double-blind, randomised, placebo-controlled trial. Mol Nutr Food Res 2015;59:240-9.

8. Jun MG, Bing XX, De JD, Qiong L, Hong HM. Effects of daidzein on estrogen receptor-positive and negative pancreatic cancer cells in vitro. World J Gastroenterol 2004;10:860-3.

9. Sanjiv K, Jagadish VK. Effect of daidzein on cisplatin-induced hemotoxicity and hepatotoxicity in experimental rats. Indian J Pharm 2017;49:1-6.

10. Kale MS, Laddha KS. Isolation, Characterization and quantification of isoflavone in Momordica dioica Roxb. Ex wild (Cucurbitaceae) fruits. Int J Appl Res Nat Prod 2013;5:28-36.

11. Ellmann GL. Tissue sulfhydryl groups. Arch Biochem Biophys 1959;82:70-7.

12. Ohkawa H, Ohishi N, Yagi K. Assay for lipid peroxidases in animal tissues by thiobarbituric acid reaction. Anal Biochem 1979;95:351-8.

13. Aebi H. Catalase. In: HU Bergmeyer. Ed. Methods in Enzymatic Analysis. Vol. 3. Academic Press: New York; 1983. p. 276-86.

14. Kakkar PS, Das B, Viswanathan PNA. Modified spectrophotometric assay of superoxide dismutase. Indian J Biochem Biophys 1984;21:130-2.

15. Bancroft JD, Gamble M. Theory and practice of histological techniques. 5th ed., Churchill Livingstone Pub., Edinburgh/New York/london/Philadelphia; 2002. p. 125-38, 172-5, 184-93, 593-620.

16. Eman S, Wagdi FE, Rania RA. Tranilast ameliorates cyclophosphamide-induced lung injury and nephrotoxicity. Can J Physiol Pharmacol 2015;94:1-12.

17. Sangita S, Swarn L, Kavindra NT. The potential protective role of aqueous extract of Aegle marmelos against cyclophosphamide induced nephrotoxicity in mice. J Exp Zool 2015;18:75-82.

18. Mojtaba K, Mehdi G, Mohammad JK, Javad B, Hossein F, Nima B, et al. Protective effects of the hydroalcoholic extract of Capparis Spinosa L. against cyclophosphamide-induced nephrotoxicity in mice. J Nat Pharm Prod 2016;1-7. Doi:10.17795/jjnpp-37240

19. Agarwal AD. Pharmacological activities of Flavonoids-a review. Int J Pharm Nanotech 2011;4:1394-8. 
20. Kadon $\mathrm{KH}$, Jun Ren. Phytoestrogenic isoflavones daidzein and genistein reduce glucose toxicity induced cardiac contractile dysfunction in ventricular myocytes. Endo Res 2004;30:215-23.

21. Rasoul E, Babak H, Hamze M, Hadi S. Vitamin E ameliorates cyclophosphamide-induced nephrotoxicity. Life Sci J 2013; 10:308-13.

22. Gultekin F, Delibas N, Yasar S, Kilinc I. In vivo changes in antioxidant systems and protective role of melatonin and a combination of vitamin $\mathrm{C}$ and vitamin $\mathrm{E}$ on oxidative damage in erythrocytes induced by chlopyrifos-ethyl in rats. Arch Toxicol 2001;75:88-96.
23. Max CY, Bernard P, Roy S, Onni N, Heidi K, Seppo P, et al. The cytoprotective effect of $\alpha$-tocopherol and daidzein against Dgalactosamine-induced oxidative damage in the rat liver. Metabolism 2007;56:865-75.

\section{How to cite this article}

- Sanjiv Karale, Jagadish V Kamath. Protective role of daidzein against cyclophosphamide induced nephrotoxicity in experimental rats. Int J Pharm Pharm Sci 2017;9(6):103107. 